\title{
COMO AS AÇÕES AUTÔNOMAS INFLUENCIAM O PROCESSO DE FORMAÇÃO DA ESTRATÉGIA NA GESTÃO DO CURSO EAD DE ADMINISTRAÇÃO PÚBLICA DA UNIVERSIDADE FEDERAL DE SANTA CATARINA HOW AUTONOMOUS ACTIONS INFLUENCE THE STRATEGY FORMATION PROCESS IN THE MANAGEMENT OF PUBLIC ADMINISTRATION DISTANCE LEARNING COURSE AT UNIVERSIDADE FEDERAL DE SANTA CATARINA, BRAZIL
}

\section{Guilherme Rizzatti}

Mestre em Administração pela Universidade Federal de Santa Catarina, Florianópolis (SC), Brasil

Data de recebimento: 02-02-2016

Data de aceite: 10-02-2017

\section{Rosalia Aldraci Barbosa Lavarda}

Professora Adjunta do Departamento de Ciências da Administração da Universidade Federal de Santa Catarina, Florianópolis (SC), Brasil

\section{RESUMO}

O objetivo deste estudo foi analisar como as ações autônomas influenciam o processo de formação da estratégia (PFE) na gestão do curso de Administração Pública modalidade Educação a Distância (EaD) da Universidade Federal de Santa Catarina (UFSC). Foi adotada a metodologia qualitativa por meio de um estudo de caso. A seleção do caso foi realizada de forma intencional e por conveniência. As técnicas de coleta de dados utilizados basearam-se em pesquisa documental e entrevistas com roteiro semiestruturado com um representante de cada nível hierárquico. A análise dos dados aconteceu pela análise narrativa e técnica pattern-matching. As ações autônomas permitem modificar a estratégia da organização e tornar a organização mais flexível, pois apresenta informações e acontecimentos do dia a dia que muitas vezes fogem do que foi planejado. Os resultados evidenciaram a proposição inicial de que as ações autônomas influenciam o processo de formação da estratégia, contribuindo na interação entre o meio interno e o meio externo, aprimorando a gestão e os processos do curso.

Palavras-chave: Ações autônomas; processo de formação da estratégia; educação a distância.

\section{ABSTRACT}

This study aimed to analyze how the autonomous actions influence the strategy formation process in the management of Public Administration Distance Learning Course at Universidade Federal de Santa Catarina. A qualitative methodology was adopted by means of a case study. The selection of the case was carried out intentionally and for convenience. The data collection techniques used were document research and semi-structured script interviews with a representative from each hierarchical level. Data analysis was performed through narrative analysis and pattern-matching technique. The autonomous actions allow modifying the strategy of the organization and making it more flexible because it presents information and events of the daily routine which often run away from what was planned. The results showed the proposition established that the autonomous actions influence and change the strategy formation process, contributing positively to the course's management and processes.

Keywords: Autonomous actions; strategy formulation process; distance learning. 


\section{INTRODUÇÃO}

Para que uma organização possa desempenhar bem o seu papel no ambiente em que está inserida é necessário que esteja atenta à estratégia, tendo em vista que é por ela que saberá para onde quer ir e como fará para chegar até esse objetivo. Assim, é evidente a importância de estar atento ao processo de formação da estratégia (PFE), pois é este o estágio no qual a estratégia é formulada e planejada.

No que se refere ao PFE, a alta diretoria sempre esteve em foco. Entretanto, com o passar do tempo, começou-se a estudar a estratégia emergente, pois estudiosos e gestores passaram a acreditar que os demais níveis hierárquicos possuíam influência neste processo por meio das ações autônomas (ANDERSEN, 2000).

Nesse sentido, o objetivo deste trabalho foi estudar como as ações autônomas influenciam o PFE, buscando responder à seguinte problemática: como as ações autônomas influenciam o PFE do curso de Administração Pública modalidade Educação a Distância (EaD) da Universidade Federal de Santa Catarina (UFSC)?

Elaboramos, a partir do marco teórico, a proposição P: As ações autônomas influenciam o PFE a partir da interação com os meios interno e externo, caracterizando a estratégia emergente.

Para alcançar o objetivo estabelecido, bem como responder à questão de pesquisa em um primeiro momento, é apresentado o marco teórico expondo brevemente o conceito de estratégia e o PFE. Depois, apresenta-se o conceito de ações autônomas e, por último, uma breve conceituação do ensino superior, passando por EaD até chegar ao curso da UFSC de Administração Pública na modalidade EaD.

O presente artigo caracteriza-se como qualitativo, tendo em vista que dados quantitativos não são o foco central deste, mas sim saber como determinada realidade acontece. Entende-se como uma pesquisa descritiva, pois descreve um único objeto de estudo, caracterizando-se também como estudo de caso, já que tem profundidade e detalhamento do objeto, no caso, nas ações autônomas e na sua influência no PFE de Administração Pública EaD da UFSC.

As técnicas de pesquisa para coleta de dados foram: leitura de manuais, projeto pedagógico e outros documentos do curso para maior conhecimento de seu funcionamento, além da verificação de possíveis incongruências. Foram realizadas entrevistas com roteiro semiestruturado com o coordenador do curso, um supervisor e um tutor a fim de englobar todos os níveis hierárquicos e ter uma visão completa do curso.

Como resultado da pesquisa, encontraram-se evidências de que as ações autônomas permitem modificar a estratégia e tornar a organização mais flexível, pois apresenta informações e acontecimentos do dia a dia que, muitas vezes, fogem do que foi planejado. Os resultados evidenciaram que as ações autônomas influenciam de fato o PFE, contribuindo por meio da interação do meio interno com o meio externo, como também dos feedbacks dos tutores de forma positiva, aprimorando a gestão e os processos do curso. Desta forma, aperfeiçoam o PFE e o cotidiano do curso.

Assim, passa-se a apresentar a revisão teórica sobre PFE, ações autônomas e considerações sobre EaD, metodologia, análise dos resultados, considerações finais e as referências utilizadas para desenvolvimento deste estudo de caso.

\section{PROCESSO DE FORMAÇÃO DA ESTRATÉGIA (PFE)}

Mintzberg, Ahlstrand e Lampel (2000) entendem a estratégia como um conjunto de atividades que ocorrem simultaneamente e são indivisíveis, sendo estas atividades resultantes de um processo dinâmico e emergente, que ocorre devido às interações entre os indivíduos que exercem influência 
no cotidiano das organizações. Enquanto Chandler (1962), Ansoff (1965) e Steiner (1969) acreditam que a estratégia tem um caráter prescritivo, intencional e racional. Isto é, a estratégia precisa primeiro ser formulada, para que, então, seja possível implementá-la. Na concepção de Mintzberg (1973), esse entendimento é limitado, tendo em vista que não considera a estratégia como um processo de aprendizado de padrões - como de fato é. Portanto não considera que o desenvolvimento acontece a partir do comportamento das pessoas, além de não levar em consideração o aprendizado no decorrer do tempo.

Whittington (2003) entende que não se deve procurar o conceito de estratégia nas organizações, mas o modo como ela é formulada e exercida, ou seja, compreender a estratégia não significa conceituá-la ou criar definições, mas entender o processo de interação entre pessoas, ambiente, organização e estratégia.

O PFE começou a ser estudado nas organizações empresariais a partir da década de 1960 (HART, 1992). Tais estudos possuíam como objetivo explicar como ocorria o PFE por meio da análise de características sociais, emocionais e cognitivas dos gestores, ou seja, a forma como o gestor age, reage e decide a elaboração da estratégia da organização. Hart (1992) afirma que na literatura referente à formação de estratégia existem duas correntes teóricas: a prescritiva, que estabelece como as decisões devem ser tomadas, e a normativa, que indica como as decisões são tomadas, as quais sugiram nas décadas de 1960 e 1980, respectivamente. Nesse sentido, o autor acredita que existem os seguintes três temas que são abordados nessa literatura: racionalidade, visão e participação.

Ainda segundo o autor, a racionalidade pode ser dividida entre perfeita e imperfeita. A racionalidade perfeita surgiu na década de 1950 e entende que o gestor utiliza a racionalidade para elaborar a estratégia e controlar a sua implementação pelos funcionários (top-down) para obter ganhos financeiros, ou seja, as decisões eram vistas como perfeitas. Na década de 1960, surgiu a racionalidade imperfeita que abordava uma perspectiva diferente da anterior, considerando a capacidade do gestor de processamento de informações do ambiente e julgar as opções limitadas, tendo em vista que as suposições cognitivas e motivacionais limitavam a sua utilização, pois havia uma tendência em escoIher a primeira alternativa considerada satisfatória.

No decorrer da década de 1980, surgiu o tema da visão que contemplava aspectos da racionalidade imperfeita, mas também estava atenta à capacidade do gestor de ser um líder, motivando e permitindo que os colaboradores participassem da elaboração e implementação da estratégia. Por fim, na década de 1990, surgiu o tema da participação, que estava ligada à capacidade do gestor em permitir a autonomia dos colaboradores em elaborar, implementar e controlar a estratégia (bottom-up).

Mintzberg e Waters (1985) entendem que as estratégias deliberadas são formuladas pelos diretores da empresa, nas quais são exercidos mecanismos de controle para que seja possível implementá-las sem qualquer tipo de contratempo. Com relação às estratégias emergentes, são impostas pelo meio em que estão inseridas, ou seja, ações do governo, pressões do mercado e afins; assim, a organização é capaz de responder e interagir ao ambiente de maneira flexível e desestruturada, ou seja, uma ideia leva a outra até que seja formado um novo padrão. Mintzberg e Quinn (2001) entendem que o PFE é realizado por meio destes dois alicerces: o deliberado e o emergente. Os dois formam as extremidades de um continuum, no qual as estratégias são criadas no mundo ideal e podem ser visualizadas no mundo real em algum pronto do traçado. Mintzberg (1978) já havia desenvolvido o conceito de estratégia emergente, afirmando que se trata de uma "estratégia não planejada", ou seja, a linha de ação só é percebida como estratégia ao passo em que ela vai se desenrolando ou em que vai acontecendo. 
No entanto, não existe uma dicotomia entre a estratégia emergente e deliberada, como afirma Mintzberg, Ahlstrand e Lampel (2000, p. 267):

Nenhuma estratégia do mundo real pode ser puramente deliberada ou emergente, uma vez que uma impede o aprendizado enquanto a outra impede o controle. Assim, a pergunta passa a ser: que grau de cada uma é adequado, onde e quando?

Dessa forma, destacam a importância de ambas na construção da estratégia e na verificação de grau e forma de como a estratégia emergente influencia na deliberada, para saber como as ações autônomas influenciam o PFE.

Pode-se também adicionar um terceiro alicerce: o processo integrador de formação da estratégia, que é caracterizado pela participação de todos os níveis hierárquicos da organização, tornando esse processo mais flexível (ANDERSEN, 2004; 2013).

Destaca-se, ainda, o entendimento de que os níveis hierárquicos clássicos (estratégico, tático e operacional) são equivalentes a alto, médio e baixo escalão, entendidos no processo integrador de formação da estratégia (LAVARDA et al., 2011) como potenciais níveis de deliberação da estratégia (alto), emersão da estratégia (baixo ou operacional), cabendo ao nível médio ou tático a integração entre a deliberação e a emergência (SCHWINGEL et al., 2012) ou seja, a articulação e realização da estratégia no seu cotidiano (ANDERSEN, 2013).

\section{AÇÕES AUTÔNOMAS}

Para que seja possível o PFE, é necessário levar em consideração o processo decisório, o qual influencia como se entende e executa a estratégia. Nesse sentido, pode-se classificar o processo de tomada de decisão em top-down, bottom-up e middle-up-down.
Andrews (1971) caracterizou como top-down, por um lado, o processo com alta centralização das decisões nos gestores do nível estratégico. As informações têm sentido vertical, sempre de cima para baixo, possuindo ênfase na estratégia deliberada. Por outro lado, o processo de tomada de decisão bottom-up possibilita que as decisões sejam tomadas considerando a experiência dos gestores do nível operacional, por meio da estratégia emergente (MINTBERG; WATERS, 1985). Em relação ao processo middle-up-down, as informações advêm do nível central ou médio da organização, ou seja, quem está inserido nesse nível (intermediário) trata as informações e as articula com o nível operacional e com o nível superior, em uma troca permanente de informações e decisões. Logo, os indivíduos do nível médio conseguem interpretar os fenômenos que estão acontecendo e podem discutir ações para a modificação da estratégia (FLOYD; WOOLDRIDGE, 1992).

Levando em consideração uma perspectiva integradora, Johnson, Melin e Whittington (2003) propõem que a estratégia ocorre a partir do nível micro-organizacional, ou seja, desde o ponto em que as atividades ocorrem, quando são geradas as atitudes, as relações e as ações, mostrando a importância de se centrar na tarefa, como uma unidade de análise, na organização e nas práticas do trabalho.

Para tanto, é pertinente o entendimento da Teoria da Ação Comunicativa (TAC), proposta por Habermas (1987), nesse processo, em que a racionalidade comunicativa é entendida como o acondicionamento do sujeito em conversar e agir e, ao participar dessa interação, fornece uma oportunidade de análise e avaliação do outro (HABERMAS, 1987). Neste sentido, ele prioriza as ações de natureza comunicativa para compreender o ser humano dentro da sociedade, estudando as ações referentes à intervenção no diálogo entre diversos sujeitos, ou seja, Habermas (1988, p. 376-377) entende que a ação comunicativa constitui uma classe de interação 
"em que todos os participantes harmonizam entre si seus planos individuais de ação e perseguem, portanto, sem reserva alguma, seus fins de validade e legitimidade". O agir comunicativo, portanto, ocorre em processos interativos dos quais participam ao menos dois indivíduos que buscam compreender e chegar a um consenso sobre uma situação a fim de coordenar seus planos e ações correspondentes de forma mútua. (HABERMAS, 1989).

Relacionando a TAC com a estratégia, Whittington (1996) afirma que a estratégia é uma prática social importante, pois pode ser considerada como algo que as pessoas fazem ou como uma prática social como as demais, já que é um conceito multidimensional e situacional, voltado para a ação. No entendimento de Gonçalves (1999), as pessoas, em um primeiro momento, interagem e coordenam suas ações pelo conhecimento que partilham do mundo, já em um segundo momento, as pessoas interagem por meio das normas sociais já existentes enquanto, só depois, em um terceiro momento, as pessoas revelam algo de suas vivências, intenções, necessidades e temores, transparecendo, assim, sua interioridade.

Mintzberg e Quinn (2001) afirmam que o maior desafio do PFE é visualizar as alterações e descontinuidades sutis que podem determinar oportunidades. Para que seja possível ficar atento a tais acontecimentos é preciso fazer surgir estratégias emergentes a partir de pressupostos advindos das interações entre os agentes do processo, pois a estratégia deliberada vem se mostrando limitada, já que ignora as ações vivenciadas pela organização. Sendo assim, Mariotto (2000) afirma que por meio das ações é possível lidar com a real complexidade da prática gerencial, pois reconhece que a definição das metas é, geralmente, feita de forma simultânea e inseparável das ações, mostrando como as decisões tomadas pelos gestores, de certa forma, isoladas, podem se configurar como um todo.

Andersen (2000) conceituou tais ações como ações autônomas que são promovidas e nutridas pelos gerentes de nível médio ou baixo que, posteriormente, se tornam ou moldam a estratégia da organização. Decisões de investimento, desenvolvimento de produtos, seleção de projetos, vendas, alocação de recursos e entrada em novos mercados influenciam o desenvolvimento da estratégia da organização. Tais ações não são intencionais, mas determinam opções estratégicas futuras para a organização, podendo, portanto, surgir estratégias importantes sem a consciência dos altos gestores.

Andersen (2000) realizou uma pesquisa na qual estudou a dicotomia existente entre o planejamento estratégico e as ações autônomas de gestão, relacionando estas com o desempenho das instituições, ou seja, buscou estudar a relação entre esse processo deliberado e o emergente, respectivamente. Neste estudo, constatou que o planejamento estratégico e as ações autônomas são elementos que se complementam no que tange a formação da estratégia, facilitando o aprendizado e a adaptação de toda a organização. Ambos os processos não são mutuamente exclusivos e, muitas vezes, são elementos complementares. A partir disto, foi constatado que utilizar apenas o planejamento estratégico é menos eficaz do que a utilização deste em conjunto com mecanismos de coordenação de ações autônomas emergentes para que sejam incorporadas no planejamento. Logo, ele afirma que, optando pelas duas abordagens, simultaneamente, é possível obter um desempenho significativamente superior às organizações que utilizam apenas uma delas.

Na mesma linha, Mariotto (2003, p. 91) explicita que "o aspecto-chave da formação contínua de estratégia é a interação ininterrupta entre ação e definição de objetivos detalhados, em um processo no qual se aprende fazendo e que se desenvolve ao longo do tempo". Para Mariotto (2003), o conceito de ações não planejadas e ações planejadas fazem parte de um modelo básico de estrutura conceitual de um processo que combina emersão com intenção (MARIOTTO, 2003, p. 89). Neste 
modelo, Mariotto (2003) propõe que o planejamento estratégico tradicional (controles diagnósticos) interage com a criação contínua da estratégia (controles interativos), evidenciando que a estratégia intencionada por meio de ações planejadas leva a resultados reais, assim como as ações não planejadas. Além disso, "o modelo também incorpora a emersão de objetivos e a criação retrospectiva de sentido no segundo subprocesso, e o aprendizado estratégico (o aprendizado de laço duplo) em ambos subprocessos" (MARIOTTO, 2003, p. 91). Estes conceitos formam o que entendemos como elementos que proporcionam a ação autônoma.

\section{CURSO DE ADMINISTRAÇÃO PÚBLICA NA EDUCAÇÃO A DISTÂNCIA (EAD)}

Uma Instituição de Ensino Superior (IES) pode ser entendida como "um organismo social vivo, cujo desempenho se constitui em um processo dinâmico e complexo, dependendo de múltiplos fatores sócio-político-culturais, em interação com seus elementos estruturais e conjunturais" (LUCK, 1996, p. 155). Santos (2001), por sua vez, afirma que as IES, focadas quanto à natureza jurídica das mantenedoras, podem ser classificadas em duas categorias: públicas e privadas. Já para Brasil (2005), as IES podem ser divididas, de acordo com a organização acadêmica, em:

- universidades;

- universidades especializadas;

- centros universitários específicos;

- faculdades integradas;

- faculdades;

- institutos superiores ou escolas superiores; e

- centros de educação tecnológica.

Com relação à universidade, Meyer Junior (2004) entende que esta possui como função o ensino, a pesquisa e a extensão. O ensino é a função mais praticada e divulgada, sendo a transmissão do conhecimento acumulado ao longo da história da humanidade. A pesquisa é a produção do conhecimento e a extensão é a função de socializar o conhecimento, produzido ou repassado pela universidade, colocando a instituição a serviço da sociedade.

Atualmente, muitas universidades públicas vêm investindo no sistema de EaD, como forma de abranger um número maior de estudantes, como afirma Nunes (1994). Para Nunes (1994), a EaD constitui-se como um recurso essencial no atendimento de grandes contingentes de alunos, de forma mais efetiva que outras modalidades e sem riscos de reduzir a qualidade dos serviços oferecidos em decorrência da ampliação da clientela atendida. Isso tudo foi facilitado pelas novas tecnologias nas áreas de informação e comunicação, que estão abrindo novas possibilidades para os processos de EaD. Corroborando este pensamento, Finger (1997, p. 14) ressalta: "pelo fato de a educação superior pública sempre ter sido oferecida em número muito menor do que de candidatos, assegurou, nesses anos todos, há confortável segurança de que, independentemente da qualidade do produto ou dos serviços, sempre haveria interessados".

Para Chaves (1999), EaD, fundamentalmente, é o ensino que ocorre quando quem ensina e quem aprende estão separados por tempo ou distância, sendo esta última a mais enfatizada. A EaD possibilita cursos para diversos níveis de escolaridade e também está presente na educação não formal como cursos de atualização e treinamentos -, em temas com caráter inclusivo.

A EaD possui características específicas que, de acordo com Aretio (1994), são: a separação professor-aluno; utilização de meios técnicos; organização de apoio tutorial; aprendizagem independente e flexível; comunicação bidirecional (por meio de feedbacks); enfoque tecnológico e comunicação massiva. Para Preti (1996, p. 45), o sistema de EaD deve ser composto por "concepção e produção de materiais didáticos, distribuição dos mesmos, direção de comunicação, condução 
do processo de aprendizagem e de avaliação, centros ou unidades de apoio". Nonato e Pinto (2013) entendem que a EaD tem enorme importância nos cursos, pois, por meio desta modalidade, é possível atender um grande número de alunos sem prejudicar a qualidade do ensino. No entanto, salientam que essa modalidade exige um maior comprometimento do aluno, exigindo muito mais disciplina e vontade de aprender do que a modalidade presencial, uma vez que o aluno deve exercer sua autonomia, possibilitando uma maior efetividade no aprendizado.

A Universidade Federal de Santa Catarina (UFSC) começou a atuar na modalidade a distância em 1995, ao idealizar um programa de formação para a Secretaria de Estado da Educação de Santa Catarina. Segundo o Projeto Pedagógico do Curso de Administração Pública da UFSC (2009), a Secretaria de Educação a Distância foi criado em 2005 com a finalidade de oferecer suporte à modalidade. A UFSC é uma das instituições integrantes do Sistema Universidade Aberta do Brasil (UAB), projeto criado pelo Ministério da Educação (MEC) em 2005, com o intuito de ampliar a oferta de cursos de graduação em instituições públicas.

Em 2009, iniciou-se o curso de Administração Pública em EaD, com o objetivo de suprir a demanda por pessoas capacitadas na área de Gestão Pública em organizações governamentais. As diretrizes consideradas na proposta metodológica para formação do curso de Administração Pública EaD da UFSC, segundo o projeto pedagógico (2009, p. 14) são:

I. Nortear a concepção, criação e produção dos materiais didáticos, de forma que contemplem e integrem os tipos de saberes, hoje reconhecidos como essenciais às sociedades do Século XXI: os fundamentos teóricos e princípios básicos dos campos de conhecimento; as técnicas, as práticas e os fazeres decorrentes destes; e o desenvolvimento das aptidões sociais ligadas ao convívio ético e responsável.

II. Promover, permanentemente, instrumentalização dos recursos humanos envolvidos no domínio dos códigos de informação e comunicação, bem como suas respectivas tecnologias, além de estimular o desenvolvimento do pensamento autônomo, da curiosidade e da criatividade.

III. Selecionar temas e conteúdos que reflitam, prioritariamente, os contextos das realidades vividas pelos estudantes nos diferentes espaços de trabalho, como também nas esferas local e regional.

IV. Adotar um enfoque pluralista no tratamento dos temas e conteúdos, recusando posicionamentos unilaterais, normativos ou doutrinários.

V. Nortear as atividades avaliativas de aprendizagem, segundo uma concepção que resgate e revalorize a avaliação enquanto informação e tomada de consciência de problemas e dificuldades, com o objetivo de resolvê-los.

VI. Em síntese, as diretrizes do curso devem oportunizar formação que privilegie competências profissionais, sociais e políticas, baseadas nos aspectos técnico-científico, ético-humanístico e político-social. (BRASIL, 2009, p. 14)

As IES possuem características peculiares e, portanto, possuem uma estrutura diferenciada, como organização dos profissionais, utilização da tecnologia, definição de metas e tomada de decisão. Assim sendo, é preciso preocupar-se além da formulação da melhor estratégia por meio de ferramentas comumente utilizadas ou adaptadas em setores genéricos.

Nesse sentido, percebe-se que as ações autônomas fazem parte da estratégia emergente, que exercem influência na estratégia deliberada das 
organizações, podendo alterá-la. Logo, em um tipo de organização como uma instituição de ensino pública, que possui estratégias bem diferentes de instituições privadas, é possível fornecer informações diferentes a respeito de como ocorre essa influência.

\section{METODOLOGIA}

O presente estudo possui uma abordagem qualitativa, já que nas ciências sociais há uma preocupação com o nível de realidade que não pode ser quantificado, procurando entender, portanto, significados, motivos, aspirações, crenças, valores, atitudes e afins (MARCONI; LAKATOS, 2007). Mesmo que a pesquisa qualitativa esteja fortemente ligada a aspectos subjetivos, é preciso considerar as questões de validade e confiabilidade para que o estudo seja considerado robusto. A validade, portanto, diz respeito a estabelecer medidas operacionais, como a utilização de múltiplas fontes de evidências e a possibilidade de generalização analítica. Enquanto a confiabilidade seria o imperativo de se documentar os procedimentos adotados ao longo do estudo ou protocolo, composto por a) fontes de evidência e procedimentos de coleta de dados, e b) definição da análise das evidências coletadas - detalhados no decorrer desta seção. Para ampliar a confiabilidade do estudo, é realizada a padronização das anotações de campo, verificando-se a segurança dos dados e os procedimentos (YIN, 2015).

A pesquisa também se caracteriza por uma pesquisa descritiva, pois descreve o objeto de estudo - no caso o curso de Administração Pública EaD da UFSC - tais quais seus dados e características, procurando apresentá-los com a maior exatidão possível, envolvendo configuração, estrutura, atividades, mudanças e relacionamentos com outros fenômenos, como também procurando ilustrar a complexidade da situação e os aspectos envolvidos (GODOI; BANDEIRA-DE-MELO; SILVA, 2006). Em relação aos meios de investigação, esta pesquisa se caracteriza por ser um estudo de caso, pois foca na compreensão dentro de um cenário individual, podendo empregar níveis múltiplos de análise dentro do estudo, combinando técnicas de coletas de dados (YIN, 2015).

No que tange a seleção do caso, o estudo foi realizado na UFSC no curso de Administração Pública modalidade a distância. A seleção do caso foi de caráter intencional pela participação dos pesquisadores na instituição, propiciando maior conhecimento por parte dos pesquisadores a respeito das peculiaridades da mesma.

Quanto ao protocolo, passamos a detalhar as fontes de evidência e procedimentos de coleta e análise de dados. A principal técnica de coleta de dados foi a entrevista com roteiro semiestruturado. As entrevistas foram desenvolvidas com o coordenador do curso, um supervisor e um tutor. Optou-se por esses três cargos, pois cada um representa uma parte da hierarquia da instituição. Sendo assim, é possível ter uma compreensão de todos os pontos de vista a respeito do problema de pesquisa. Utilizou-se também uma pesquisa de documentos e manuais do curso que puderam trazer maior entendimento da estrutura do curso e dos processos.

Seguindo os conceitos de formação da estratégia e ações autônomas de Mintzberg (1978), Mintzberg e Waters (1985) e Andersen (2000; 2004) foram elaboradas as principais questões norteadoras das entrevistas: Como ocorre o PFE no curso? Como os supervisores e tutores participam do PFE? Que tipo de acontecimento/atitude/ constatação ocorreu que possa ilustrar a dinâmica da estratégia do curso? Como esse acontecimento/episódio modificou algum processo/atividade (etc.) da organização? De que forma ocorre o processo de tomada de decisão no curso? Com respeito às normas, atividades e escolha do NDE, quem participa e como? Como são as reuniões, encontros e quem faz as atas? 
Como técnica de análise dos dados, o conteúdo das entrevistas e a pesquisa documental foram estudados com base na análise narrativa, entendida por Godói, Bandeira de Mello e Silva (2006) como uma forma de capturar a complexidade e a inter-relação dos fenômenos, em que se apresenta a sequência dos acontecimentos relacionados em um contexto de tempo e assunto. Além da análise narrativa, foi utilizado o modelo de correspondência de padrão (pattern-matching), que, segundo Trochim (1989), é um modelo que liga dois padrões, sendo um teórico e o outro observado ou operacional (vindo da triangulação dos dados da pesquisa empírica). Yin (2015) corrobora esta técnica, apontando que é uma abordagem em que diversas partes da informação de um mesmo caso podem ser relacionadas com proposições teóricas.

Para tornar a fase da análise mais simplificada, adotaram-se as categorias de análise (CA) de acordo com Kerlinger (1979). Buscou-se relacionar a questão de pesquisa $(\mathrm{Q})$, a proposição teórica $(\mathrm{P})$, as categorias de análise (CA) e os respectivos conceitos, como elementos norteadores do estudo empírico, possibilitando verificar os dados com a proposição formulada teoricamente (Quadro 1), ou seja, verificar o que de fato ocorre no curso e como as ações autônomas influenciam o PFE na visão de cada cargo a partir do que está documentado.

\section{APRESENTAÇÃO E ANÁLISE DOS DADOS}

Os resultados da coleta de dados obtidos por meio de entrevistas semiestruturadas foram tratados conjuntamente com o estudo de documentos por meio da utilização da análise narrativa de Godoi, Bandeira-de-Mello e Silva (2006), e da técnica pattern-matching de Trochim (1989). Nesse sentido, para essa etapa utilizaram-se as categorias de análise de Kerlinger (1979), que serão apresentadas a seguir.

\subsection{CA1: PFE}

A respeito dos resultados encontrados por meio da análise dos dados, percebeu-se que o PFE, no que tange a estratégia deliberada (MINTZBERG; WATERS, 1985), foi identificado nas deliberações recebidas do MEC, isto é, o plano pedagógico já vem com suas diretrizes fixadas pelo MEC, pois é um programa nacional; entretanto, o coordenador possui autonomia para tomar decisões e realizar modificações desde que não sejam contra as diretrizes já estabelecidas. A criação do cargo de supervisor é um exemplo, a qual ocorreu apenas nessa instituição pois se verificou a necessidade de um suporte entre os tutores e a coordenação.

Quadro 1 - Questão de pesquisa, proposição e categorias de análise

\begin{tabular}{|c|c|c|c|}
\hline $\begin{array}{l}\text { Questão de pesquisa } \\
\text { (Q) }\end{array}$ & $\begin{array}{l}\text { Proposição teórica } \\
\text { (P) }\end{array}$ & & Categorias de análise (CA) \\
\hline \multirow{4}{*}{$\begin{array}{l}\text { Como as ações } \\
\text { autônomas influenciam } \\
\text { o PFE do curso de } \\
\text { Administração Pública } \\
\text { modalidade EaD da UFSC? }\end{array}$} & \multirow{4}{*}{$\begin{array}{l}\text { As ações autônomas } \\
\text { influenciam o PFE a } \\
\text { partir da interação } \\
\text { com o meio } \\
\text { interno e externo, } \\
\text { caracterizando a } \\
\text { estratégia emergente }\end{array}$} & \multirow{3}{*}{ CA1: PFE } & $\begin{array}{l}\text { Estratégia deliberada - formulada pelos diretores da } \\
\text { organização na qual são exercidos mecanismos de controle } \\
\text { (MINTZBERG; WATERS, 1985). }\end{array}$ \\
\hline & & & $\begin{array}{l}\text { Estratégia emergente - linha de ação que só é percebida } \\
\text { como estratégica pela organização à medida que ela vai } \\
\text { acontecendo ou até mesmo depois que já aconteceu } \\
\text { (MINTZBERG, 1978). }\end{array}$ \\
\hline & & & $\begin{array}{l}\text { Estratégia integradora - participação de todos os níveis } \\
\text { hierárquicos da organização na tomada de decisão } \\
\text { (ANDERSEN, 2004). }\end{array}$ \\
\hline & & \multicolumn{2}{|c|}{$\begin{array}{l}\text { CA2: Ações autônomas: ações promovidas e nutridas pelos gerentes de } \\
\text { nível médio no cotidiano, as quais acontecem de forma independente e que, } \\
\text { posteriormente, moldam a estratégia (ANDERSEN, 2000). }\end{array}$} \\
\hline
\end{tabular}

Fonte: Elaboração própria 
A estratégia deliberada ocorre com o próprio coordenador, no Núcleo Docente Estruturante (NDE), no colegiado do curso e pelo MEC no que se refere às diretrizes já estabelecidas, tendo em vista que elas são a base da estratégia do curso. A coordenação informa as estratégias e diretrizes para os supervisores, estabelecendo o plano de ação do nível tático, que, por sua vez, estabelecem o plano de ação do nível operacional.

O NDE é um fórum de discussão para alterações do curso, todavia, os professores tornam-se passivos nas reuniões, pois não participam efetivamente no cotidiano da organização, logo, os tópicos e propostas são iniciados pelo coordenador. Como exemplo, o NDE pode regulamentar o Trabalho de Conclusão de Curso (TCC), as disciplinas, o conteúdo de algumas disciplinas e alguns pontos do processo pedagógico. O Colegiado, por sua vez, tem uma esfera mais ampla e ambos são institucionalizados. Certas questões devem ser obrigatoriamente discutidas e decididas nelas, porém, de modo geral, o coordenador toma as decisões sozinho ou com o auxílio do grupo consultivo, levando em consideração o tempo para a tomada de decisão. Vale ressaltar que quem responde pelas decisões e, portanto, deve homologá-las é o coordenador do curso.

No que tange a estratégia emergente, o grupo consultivo - grupo informal para discussão, do qual fazem parte a coordenação e os supervisores - se reúne semanalmente, em reuniões informais, para contextualizar o andamento do curso e para soluções de eventuais problemas encontrados pelo nível tático ou operacional. Em determinados processos, há um possível caráter integrador, pois assume um papel deliberado em certos momentos, apesar de a emergência ser mais característica. O coordenador do curso evidencia a frequência dessas reuniões: "[...] nós temos uma reunião toda semana, toda segunda-feira. A gente se reúne, e traz algumas ideias... Às vezes os problemas surgem e, a partir disso, a gente sai atrás da solução".
Além dessas reuniões, os supervisores realizam encontros com os tutores, nos quais eles participam opinando sobre o assunto. Caso seja necessário, pode ocorrer de forma esporádica uma reunião com os três níveis hierárquicos, que, de forma geral, tem caráter informal e motivacional. Nesse sentido, é visível uma estratégia integradora, pois o curso possui uma conexão da estratégia deliberada e emergente, como o coordenador evidencia:

As ações do curso, algumas sou eu e outras eu tenho um colegiado. É eu, a Joana, que é subcoordenadora, mais a Cida e o Roberto, que são os supervisores. Algumas decisões nós tomamos em conjunto, assim, mas sempre, por se tratar de serviço público, eu é que tenho que homologar essa decisão, porque, como eles não são servidores e a Joana é subcoordenadora, sempre tem que passar por mim. Mas, às vezes, eu escuto eles porque eles podem ter informações e experiência que pode ajudar.

Ainda sobre a estratégia integradora, é possível observá-la na seguinte afirmação do coordenador, observando a abrangência da estratégia tanto de forma deliberada quanto emergente na tomada de decisões:

Existem quatro possibilidades de tomada de decisão: a individual são as situações que eu posso decidir sem passar por colegiado nem NDE. Eu tenho um grupo que é o grupo consultivo dentro do curso que nós criamos, que é eu, como presidente, a Joana, como subcoordenadora, o Roberto, do PNAP1, e a Cida, que é supervisora do PNAP2 e 3. Nós temos uma espécie de colegiado (informal), a gente se reúne toda segunda-feira para discutir situações do dia a dia e, muitas vezes, para sugerir alguma ideia; são atividades administrativas e operacionais e que vão encontrar solução para algum problema. E tem o NDE e o colegiado, que é uma esfera institucionalizada (formal), faz parte da universidade, a constituição do NDE faz parte 
da universidade, assim como o colegiado, e tem situações onde a legislação determina que eu sou obrigado a passar pelo NDE e colegiado, então tem situações que eu posso decidir sozinho. Tem situações onde eu vou utilizar a Joana, o pessoal do meu grupo, e tem situações onde eu tenho que passar pelo NDE e colegiado, não tem outra maneira de fazer as coisas sem passar por ali, porque eu tenho que observar a lei, sou servidor público.

\subsection{CA2: Ações autônomas}

Nas ações autônomas, considerando o conceito de Andersen (2000), pode-se verificar algumas situações. Uma dessas foi quando os tutores verificaram que a atividade de videoconferência - atividade pela qual os alunos se dirigiam até o polo e interagiam com o professor ao vivo - estava falha, pois os alunos faltavam constantemente, os professores esqueciam-se de se deslocar até as salas de filmagem, ou ninguém sabia o que falar. Após essa constatação, os tutores a encaminharam para a supervisão, que buscou mecanismos para incentivar os alunos a estarem presentes e, após diversas tentativas sem sucesso, informaram a coordenação por meio de uma reunião, concluindo que essa estratégia de interação entre professor e aluno não estava sendo eficiente e, portanto, precisaram modificá-la. Como nova estratégia, passou-se a utilizar a metodologia de que, caso algum aluno tenha dúvida, este deve enviar um e-mail e, como resposta, o professor deve gravar um vídeo e encaminhar para todos os alunos para que eles tenham acesso a esse questionamento.

Outro fato identificado foi um problema recorrente na matrícula da disciplina "Seminário Temático" da quinta fase, no qual o aluno deveria optar entre uma das três linhas que desejava, ou seja, em uma das três disciplinas; porém, o sistema de matrícula obrigava o aluno a se matricular nas três disciplinas, tendo em vista que a matrícula das disciplinas obrigatórias não é facultativa. Para realizar a matrícula, o aluno precisava se inscrever nas três disciplinas e indicar ao tutor qual das três ele desejava cursar para que eles pudessem entrar no sistema e excluir as outras duas manualmente. Para resolver essa questão, a supervisão sugeriu que fosse criado apenas uma disciplina genérica e o aluno informaria ao tutor qual linha ele desejava cursar, o que foi acatado pela coordenação.

Esse problema mostra, por um lado, que, mesmo com a ideia correta de implementação, nem sempre a tecnologia nos fornece os meios ideais. Por outro lado, essa ação coincide com o que foi visto na teoria sobre as ações de natureza comunicativa para compreender o ser humano dentro da sociedade, as ações referentes à intervenção no diálogo entre diversos sujeitos, propostas por Habermas (1988, p. 376-377) quando se refere à ação comunicativa como uma classe de interação "em que todos os participantes harmonizam entre si seus planos individuais de ação e perseguem, portanto, sem reserva alguma, seus fins de validade e legitimidade", o que pode levar à modificação de processos estabelecidos.

Além dos fatos anteriormente citados, ocorreu também a constatação de plágios por parte dos tutores, e, após o grande número de casos, ficou entendido que era necessária uma reunião para mudar a estratégia do curso em relação a esses casos. Sendo assim, foi realizado um encontro com toda a coordenação, supervisão e tutoria para implementar uma linha de ação uniforme. Nessa oportunidade, os tutores participaram ativamente do PFE, pois tanto a supervisão quanto a coordenação não possuem esse contato e conhecimento dos detalhes dos tipos de casos que ocorrem e da peculiaridade de cada turma e polo. Nesse encontro, entendeu-se que os alunos deveriam enviar com o TCC uma declaração de que não se fez uso de plágio, isentando o orientador e o curso de qualquer responsabilidade referente a essa prática. Além disso, implementaram avisos sobre a 
repetência do aluno e a possibilidade de um processo administrativo.

\subsection{Relação entre as categorias de análise}

Quando investigado sobre a participação dos níveis tático e operacional no PFE, identificou-se que o coordenador e o supervisor acreditam que ambos os níveis participavam, menos o operacional, apesar de eles fornecerem feedbacks e apresentarem situações que ocorrem no cotidiano. Curiosamente, o entrevistado do nível operacional tem maior ciência de sua participação no processo, afirmando fazer parte deste, não de maneira formal, mas com as ações diárias, do próprio cotidiano, que requerem ações rápidas e modificam o processo; o entrevistado acredita, ainda, que todos os processos estão se modificando periodicamente.

No que tange ao processo de tomada de decisão no curso, cada colaborador tem autonomia quanto a suas atribuições. Com relação aos supervisores, estes costumam dar ciência para a coordenação a respeito das ações tomadas, além de que suas atribuições são de criação do calendário, cronograma dos tutores, gerenciamento de faltas, escala dos chats e suporte para os tutores no que se refere a dúvidas. Qualquer decisão estratégica quem toma é o coordenador, apesar de que, em diversas situações, os supervisores propõem ações que ele (coordenador) acata, tendo em vista a sua percepção de que, pelo fato de os supervisores e os tutores estarem em maior contato com os alunos e com o operacional, eles possuem maior embasamento e conhecimento tácito sobre determinados assuntos. Além disso, o coordenador nunca interfere nas decisões de atribuição desses cargos, todavia, está sempre cobrando resultados.

A respeito dos tutores, eles possuem total autonomia no que se refere a sua interação com os alunos e participam do PFE (deliberadamente) por meio de reuniões convocadas (formalmente) com os supervisores, que acabam repassando as situações para as reuniões com a coordenação.

Caracteriza-se, assim, a estratégia emergente, como linha de ação que só é percebida como estratégica pela organização à medida que ela vai acontecendo ou até mesmo depois que já aconteceu (MINTZBERG, 1978), o que foi evidenciado nas atividades de contato direto com os alunos, fornecendo informações para futuras modificações e influências no PFE. Em virtude de alguma situação atípica, os alunos entram em contato com o professor da disciplina ou com o supervisor, sendo que todos os tutores recebem dúvidas e resposta por meio eletrônico, compartilhando a informação, para conhecimento de todos do procedimento adotado, sendo este novo ou não.

\subsection{Análise da questão de pesquisa e proposição}

As situações anteriormente identificadas e citadas mostraram-se como influentes e até mesmo modificaram a estratégia da organização, como foi evidenciado. Os entrevistados entenderam que essas ações diminuíram o desgaste deles com o passar do tempo, situações que foram identificadas e que foram incorporadas ao processo, resultando em menos problemas, evitando conflitos e perda de tempo, além de ganho de maior eficiência. Como afirma o coordenador:

Gerou menos incômodo, menos desgaste. Na administração pública, as coisas empacam muito na observância da legislação, não é que empacam, nós temos que observar muito a legislação, e aí, na medida em que a gente encontra uma falha, alguma coisa que pode ser melhorada, com certeza a gente procura, de alguma forma, evitar problemas que possam acontecer na relação entre a instituição, a coordenação e os alunos. Não dá pra dizer que é questão só de tempo, mas principalmente de evitar realmente conflitos entre a instituição e o aluno. 
Os processos e a relação interna entre os colaboradores foram aprimorados, além de o contato do tutor com o aluno e deste com o tutor ter melhorado, aperfeiçoando a rotina. A resposta da coordenação para os supervisores é dada rapidamente, pois a coordenação entende que quem está na linha de frente (tutores e supervisores) possui maior compreensão da realidade em que estão inseridos, logo, têm maior conhecimento para tomar decisões quanto a essa realidade, além de buscar sempre se antecipar a situações futuras e buscar sempre a inovação.

Assim, considerando a questão de pesquisa "Como as ações autônomas influenciam o PFE do curso de Administração Pública modalidade EaD da UFSC?" e a proposição "As ações autônomas influenciam o PFE a partir da interação com o meio interno e externo, caracterizando a estratégia emergente", percebe-se que, efetivamente, as ações autônomas fazem parte da estratégia emergente, a qual exerce influência na estratégia deliberada das organizações, podendo alterá-la.

Considerando o tipo de organização - instituição de ensino pública - que possui estratégias diferentes de instituições privadas, entende-se que as ações autônomas sejam mais limitadas devido ao "engessamento", à quantidade e à variedade de processos, com o "agravante" de o curso analisado ser EaD, o qual requer maior nível, ainda, de "amarras", pois todos os procedimentos devem ficar devidamente registrados, nada pode ser feito sem que se "emita um parecer ou faça o devido registro".

Portanto, de acordo com as evidências apresentadas nas categorias de análise, entende-se que a questão de pesquisa foi respondida com a proposição, sendo corroborada com os dados empíricos e apontando como ocorrem as ações autônomas ao influenciarem o PFE do curso de Administração Pública modalidade EaD da UFSC, ou seja, as ações da emergência estratégica modificam a estratégia deliberada, o que leva a um processo integrador de formação da estratégia.
Com o feedback dos tutores (a partir das interações com os professores e alunos) pode-se evidenciar que o curso possui o PFE de forma integradora, conforme os estudos de Andersen (2004), e que as ações autônomas, sejam dos tutores ou dos supervisores, influenciam diversas vezes esse processo, caracterizando a emergência estratégica de Mintzberg (1978) e otimizando os mesmos, além de modificar o dia a dia do curso, segundo o que tinha sido anteriormente previsto na estratégia deliberada (plano pedagógico).

\section{CONSIDERAÇÕES FINAIS}

O objetivo deste estudo foi analisar como as ações autônomas influenciam o PFE no curso de Administração Pública EaD da UFSC. Foi possível perceber que o curso adotou um PFE integrador, na perspectiva de Andersen (2004), considerando a organização do setor público e, mesmo assim, possuir uma interação de níveis hierárquicos e entre tutores e alunos.

Nesse sentido, as ações autônomas (Andersen, 2000) se mostraram influentes no PFE, pois as interações com os alunos, bem como entre os colaboradores do nível médio e operacional, conduziram a novas perspectivas da realidade na estratégia da organização.

O gestor (coordenador), frequentemente, toma decisões em conjunto com o grupo consultivo e, quando toma alguma decisão sozinho, em grande parte das vezes usa informações advindas do nível operacional e tático. Logo, mesmo tratando-se de uma organização pública e, por consequência, possuir formalismos devido à burocracia inerente do setor, o gestor propicia um ambiente no qual todos possam participar e, com isso, as ações autônomas conseguem dar frutos e aperfeiçoar cada vez mais a estratégia do curso. A autonomia dos cargos mostrou-se forte e trabalha de forma a contribuir para que surjam mais ações autônomas no decorrer 
dos dias e, consequentemente, otimizando a gestão do curso.

Outro fator interessante encontrado neste estudo foi a constatação de que os níveis estratégico e operacional não identificavam o nível operacional como participante do PFE, mesmo ele (operacional) contribuindo com diversas ações, ideias e fatos, o que acaba sendo contraditório; provavelmente, essa visão está atrelada à crença de que a estratégia acontece apenas de forma deliberada, de acordo com os conceitos de Mintzberg e Waters (1985). Os tutores parecem perceber mais a sua influência nesse processo e acreditam realmente fazer parte dele, por meio das informações apresentadas aos seus superiores, mesmo não fazendo parte da estratégia formal ou deliberada.

Assim, as ações autônomas, conforme previsto por Andersen (2000), fazem parte da estratégia emergente, a qual exerce influência na estratégia deliberada da coordenação do curso, podendo alterá-la.

As limitações deste estudo se enquadram nos aspectos relacionados ao número reduzido de entrevistados, o qual pode não abranger toda a realidade do curso. Destaca-se que a realização de um único caso também precisa ser superada.
Como sugestão para novas pesquisas, sugere-se dar continuidade a esta pesquisa, com maior profundidade na coleta de dados sobre o processo, buscando utilizar a técnica de observação e a entrevista semiestruturada, além de fazer uma análise mais consistente nos documentos do curso, entrevistando mais colaboradores, o que não foi possível devido à greve pela qual a universidade atravessou durante todo o período da pesquisa. Outra linha de pesquisa seria fazer um estudo detalhando o processo de ações autônomas e verificando desde o surgimento até as discussões e implementações destas ações na estratégia organizacional, assim como fazer um estudo comparativo com uma IES privada.

Pode-se apontar, por um lado, como contribuição deste estudo, a compreensão da importância das ações autônomas no PFE para os gestores do curso, as quais foram destacadas como positivas.

Por outro lado, foi possível verificar a influência das ações autônomas em uma organização pública que, geralmente, é considerada uma organização totalmente voltada para a estratégia deliberada (burocrática). Além disso, este estudo contribuiu para o amadurecimento da gestão do curso, que pôde perceber a relevância das ações autônomas e entender melhor o funcionamento do PFE em sua gestão.

\section{REFERÊNCIAS}

ANDERSEN, T. J. Strategic planning, autonomous actions and corporate performance. Long Range Planning, Vienna, v. 33, n. 2, p. 184-200, 2000.

Integrating the Strategy Formation Process: An International Perspective. European Management Journal, Glasgow, v. 22, n. 3, p. 263-272. 2004.

\section{Shortintroduction to Strategic Management.}

Cambridge: University Printing House, 2013.

ANDREWS, K. R. The Concept of Corporate Strategy. New York: Dow Jones-Irwin, 1971.
ANSOFF, I. Estratégia empresarial. São Paulo: McGrawHill, 1965.

ARETIO, L. G. Educación a distancia hoy. Madrid: Universidad Nacional de Educación a Distancia, 1994.

BRASIL. Ministério da Educação Superior. Organização da Educação Superior. Disponível em: <http://portal. mec.gov.br/sesu>. Acesso em: 19 jul. 2015.

CHANDLER, A. Strategy and structure. Cambridge: MIT Press, 1962. 


\section{REFERÊNCIAS}

CHAVES, E. O. C. Tecnologia na educação, ensino a distância e aprendizagem mediada pela tecnologia. Campinas, 1999. Disponível em: <http://bit. ly/2nZ8MRX>. Acesso em: 4 abr. 2017.

FINGER, A. P. (Org.). et al. Gestão de Universidades: novas abordagens. Curitiba, Champagnat, 1997.

FLOYD, S. W.; WOOLDRIDGE, B. Middle Management Involvement in Strategy and its Association with Strategic Type: A Research Note. Strategic Management Journal, New Jersey, n. 13, p. 153-167, 1992.

GODOI, C. K.; BANDEIRA-DE-MELLO, R.; SILVA, A. B. Pesquisa qualitativa em estudos organizacionais: paradigmas, estratégias e métodos. São Paulo: Saraiva, 2006.

GONÇALVES, M. A. S. Teoria da ação comunicativa de Habermas: possibilidades de uma ação educativa de cunho interdisciplinar na escola. Educação \& Sociedade, Campinas, v. 20, n. 66, p. 125-140, 1999.

HABERMAS, J. Teoria de la acción comunicativa l: racionalidad de la acción y racionalización social. Madrid: Taurus, 1987.

Teoria de la acción comunicativa. Trad. Manuel Jiménez Redondo. Madrid: Taurus, 1988.

Consciência moral e agir comunicativo. Rio de Janeiro: Tempo Brasileiro, 1989.

HART S. L. An Integrative Framework for StrategyMaking Processes. Academy of Management Review, New York, v. 17, p. 327-351, 1992.

JOHNSON, G.; MELIN, L.; WHITTINGTON, R. Micro Strategy and Strategizing: Towards an Activity-Based
View. Journal of Management Studies, New Jersey, v. 40 , n. 1, p. 3-22, 2003.

KERLINGER, F. N. Behavioral research: A conceptual approach. New York: Holt, Rinehart, and Winston, 1979.

LUCK, H. Gestão educacional: estratégia para a ação global e coletiva no ensino. In: Educação: caminhos e perspectivas. Curitiba: Champagnat, 1996.

MARCONI, M. A.; LAKATOS, E. M. Metodologia científica. 5. ed. São Paulo: Atlas, 2007.

MARIOTTO, F. L. Mobilizing emergente strategies. Relatório n. 10/2000. Núcleo de Pesquisas e Publicações. São Paulo: Eaesp/FGV, 2000.

Mobilizando estratégias emergentes. Revista de Administração de Empresas, São Paulo, v. 43, n. 2, p. 78-93, 2003.

MEYER JR., V.; MOREIRA, J. L. Extensão universitária: uma análise da experiência do curso de Medicina Veterinária da PUCPR. Revista Acadêmica, Curitiba, v. 2, n. 4, p. 55-61, 2004.

MINTZBERG, H. Strategic making in three modes. California Management Review, Berkeley, p. 44-53, 1973

Patterns in strategy formation. Management Science, v. 29, n. 9, p. 934-48, 1978.

MINTZBERG, H.; AHLSTRAND, B.; LAMPEL, J. Safári da estratégia: um roteiro pela selva do planejamento estratégico. Porto Alegre: Bookman, 2000.

MINTZBERG, H.; QUINN, J. B. O processo da estratégia. 3. ed. Porto Alegre: Bookman. 2001 


\section{REFERÊNCIAS}

MINTZBERG, H.; WATERS, J. A. Of strategies, deliberate and emergent. Strategic Management Journal, Catonsville, v. 6, n. 3, p. 257-272, 1985.

NONATO, H.; PINTO, E. Educação a distância - vantagens e desvantagens. Disponível em: <http://bit.ly/2nAU0xl>. Acesso em: 4 abr. 2017.

NUNES, I. B. Noções de Educação a distância. 1994. Disponível em: <http://bit.ly/1cjhP82> Acesso em: 4 abr. 2015.

PRETI, O. Educação a Distância: uma prática educativa mediadora e mediatizada. Cuiabá: Nead/IE -UFMT. 1996.

SANTOS, E. M. Modelo conceitual de sistema de custos por atividades para as universidades: um estudo de na Universidade do Vale do Itajaí. 2001. 151 f. Dissertação (Mestrado) Universidade Federal de Santa Catarina, Florianópolis. 2001

STEINER, G. Top management planning. London: The McMillan Company, 1969.

SCHWINGEL, A. T. ; GENEROSO, P. G. ; LAVARDA, R. B. A Dinâmica das Ações Cotidianas Articuladas pelos
Coordenadores e Diretores na Implementação da Estratégia. Gestão \& Regionalidade, São Paulo, v. 28, n. 84, p. 103-116, 2012.

TROCHIM, W. M. K. Outcome pattern matching and program theory. Evaluation and Program Planning, v. 12, p. 355-366, 1989.

UNIVERSIDADE FEDERAL DE SANTA CATARINA. Ministério da Educação. Coordenação de Aperfeiçoamento de Pessoal de Nível Superior. Projeto Pedagógico do Curso Bacharelado em Administração Pública a distância: Santa Catarina: Universidade Federal de Santa Catarina. Disponível em: <http://bit. ly/2oygCUh>. Acesso em: 4 abr. 2017.

WHITTINGTON, R. Strategy as practice. Long Range Planning, New York, v. 29, n. 5, p. 731-735, 1996.

National innovation and transnational variation. Keynote presentation, European Academy of Management. Bocconi University, Milan, 2003.

YIN, R. K. Estudo de caso: planejamento e métodos. 5. ed. Porto Alegre: Bookman, 2015. 